$\mathbb{T}$ periodica polytechnica

Mechanical Engineering

$52 / 1(2008) \sqrt{15}, 18$

doi: 10.3311/pp.me.2008-1.03

web: http://www.pp.bme.hu/me

(c) Periodica Polytechnica 2008

RESEARCH ARTICLE

\section{Influence of the infiltration pressure on the properties of MMC wires}

\author{
Imre Kientzl / Árpád Németh / János Dobránszky
}

Received 2008-01-18

\begin{abstract}
$M M C$ wires are ceramic fibre reinforced metal matrix composites produced by continuous infiltration method (Blucher process). During the MMC (Metal Matrix Composite) wire production it is possible to change the applied infiltration pressure which overcomes the poor wetting behaviours between the ceramic reinforcement and the molten metal. The changing of infiltration pressure has influence on the mechanical properties by the porosity of $M M C$ wires.
\end{abstract}

\section{Keywords \\ MMC wire $\cdot$ double composite $\cdot$ pressure infiltration}

\section{Acknowledgement}

This work was supported by the Hungarian Scientific Research Fund:.K69122. Special thanks to Professor J. T. Blucher and I. N. Orbulov for their kind help.

Imre Kientzl

Department of Materials Science and Engineering, BME, H-1111 Budapest, Múegyetem rkp. 5., Hungary

e-mail: imre@eik.bme.hu

\section{Árpád Németh}

Department of Materials Science and Engineering, BME, H-1111 Budapest, Múegyetem rkp. 5., Hungary

\section{János Dobránszky}

Research Group for Metals Technology, MTA, Hungary

e-mail: dobi@eik.bme.hu

\section{Introduction}

The aim of our work was to determine the relationship between the applied infiltration pressure and quantity of unfilled voids in continuous pressure infiltrated metal matrix composite (MMC) wires. In addition tensile tests were carried out to come to know the effect of infiltration pressure on the mechanical properties as well.

In case of continuous process which is a pressure infiltration method it is possible to control the parameters of production for example pulling velocity, fibre and alloy (matrix) combination and diameter of the composite wire (MMCW). During the process the melt penetrates into the fibre bundles due to the pressure [1]. The continuous infiltration technique prevents fibre degradation and greatly increases yield by virtue of the quick transport of fibres through a molten metal bath under pressure [2]. Blucher et al. described the details of the continuous pressure infiltration technique [3-5].

The Blucher-process provides practical application of fibre reinforcements in aluminium structural elements. Apart from using them directly as tension type load carrying elements or combining them into sandwich structures, a major potential application is preferential reinforcement of $\mathrm{Al}$ or $\mathrm{Mg}$ castings. The two major difficulties encountered during direct fibre reinforcement of cast parts, the required high infiltration pressure and the tendency of the reinforcing fibres to float away from their intended place, are eliminated when the fibres are introduced into the casting in the form of prefabricated MMC wires [6]. The MMC wire reinforced composites are called double composites. Another method for double composite fabrication is extrusion, which was described by Weidenmann et al. [7]

In a non-wetting metal/oxide system some impetus must be applied to overcome the interfacial energies during the production process of metal matrix composites. There are some theoretical calculation methods to estimate the necessary infiltration pressure for composite wire production. In the case of continuous pressure infiltration the threshold pressure of infiltration is normal to the fibres' axes. Kaptay's equations describe the threshold pressure as a function of the contact angle and smallest separation of the fibres divided by the fibre diameter 
[8]. The threshold pressure of non-wetting liquids is found to be inversely proportional to the smallest gap between the fibres although it is commonly believed to be inversely proportional to the diameter of the fibres. Four different cases were distinguished based on the wettability of fibres and the spaces between the fibres and the equations of threshold pressures were worked out for all these cases [8].

Matsunaga et al. present another way to produce composite wires, which is the ultrasonic infiltration method [9, 10].

Composites which contain more than one reinforcing or matrix material are called hybrid composites [11]. The mechanical properties and wettability can be increased via use of more than one type of appropriate reinforcement.

\section{Methods}

The composite wires contained 3750 filaments. Nextel 440 ceramic fibre [12] reinforced aluminium (Al 99.5) matrix composite wires of $1 \mathrm{~mm}$ diameter were fabricated by continuous process. The sizing of the filaments were removed by burning at $800^{\circ} \mathrm{C}$.

In the pressure chamber the infiltration pressure was altered in steps. The applied pressures were $0.83 \mathrm{MPa}$ (120 psi), $1.03 \mathrm{MPa}$ (150 psi), 1.24 MPa (180 psi), 1.52 MPa (220 psi), 1.65 MPa (240 psi). The distribution of the fibres can randomly change therefore 10 samples were examined in each lot so as to decrease the effect of variance in fibre distribution. The pulling velocity was $15 \mathrm{~m} / \mathrm{min}$, consequently, the exposure time (time what the fibres spent in molten metal) was approximately $0.2 \mathrm{~s}$. The samples were examined by optical microscopy and tensile test.

Samples were polished for optical microscope analysis and taking micrographs. It is important to avoid damage of the contour of ceramic fibres during metallographic preparation to ensure the precision of the measurements, so diamond suspensions were used for the last grinding steps. High resolution images were needed for precise analysis of the total cross section, which were obtained by taking a number of partial micrographs. Micrographs with overlapping edges were needed for easier fitting. Alignment of the pictures and removal of the inhomogeneous background was carried out with image editor software [13]. It is not possible to determine the volume fraction of the noninfiltrated voids with a direct method because the colour of the fibres is similar to the colour of the pores in the picture (because the contours of fibres are damaged). Therefore pores and fibres were marked with the same colour. Accordingly, the aluminium matrix was marked as white while the fibres and pores as black. It is important to save the picture files in lossless format to avoid the blur of the colours. Further information can be found about image analysis of micrographs in the literature [13].

Measurement errors due to grinding can be causes by the followings:

- the metal matrix covers the fibres
- the splintering of the ceramic fibres

Measurement errors can also arise by reason of image processing as follows:

- alignment of the pictures

- separation of the MMCW from the background in the picture

- separation of the matrix, reinforcement and pores from each other $($ matrix $=$ white; remaining area $=$ fibres and pores $=$ black)

The "volume fraction" mentioned herein is actually the proportion of the investigated component in the micrograph that is equivalent to its volume fraction.

In the case of double composites the volume fraction of fibres must be less than in the case of reinforcing composite wires because of the gap between the composite wires to be filled with the secondary matrix.

The preparation of MMC wire samples is necessary for tensile test to avoid the breakage by the clamps. To achieve this both end of the specimens were stuck into copper tubes. The stuck length was $30 \mathrm{~mm}$ to secure the sufficient force delivery. Instron universal testing machine was used with computer aided data recording. For the examinations five $150 \mathrm{~mm}$ long specimens were used from each lot.

\section{Results and discussion}

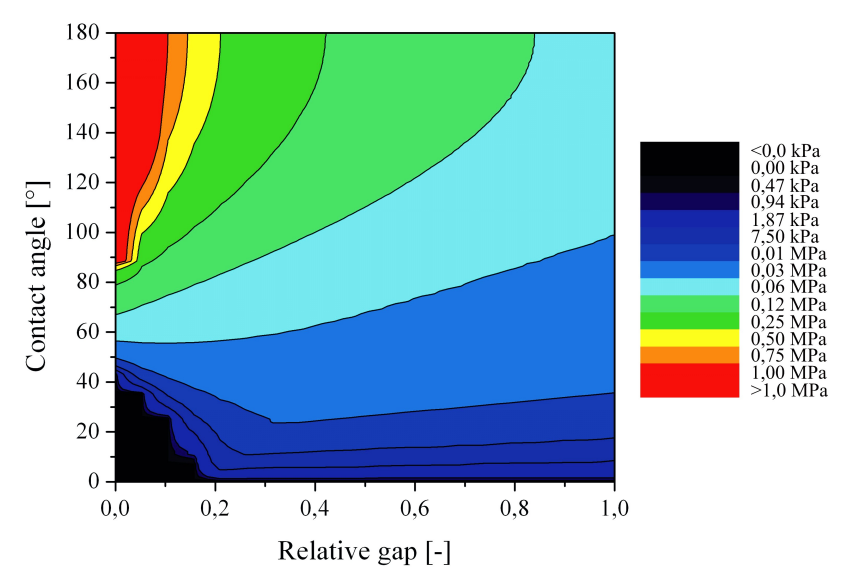

Fig. 1. Threshold pressure as function of the contact angle and smallest separation of the fibres divided by the fibre diameter

The threshold pressure was calculated and plotted as function of the contact angle and relative gap between the fibres (Fig. 1), based on Kaptay's method. The distance between the filaments in composite wires varies within a wide range but the fibres are generally in contact with each other. The ultimate value for the space between the dimensionless fibres is due to the roughness of their surface, which is never zero, and thus the calculated threshold pressure can never reach infinity. 


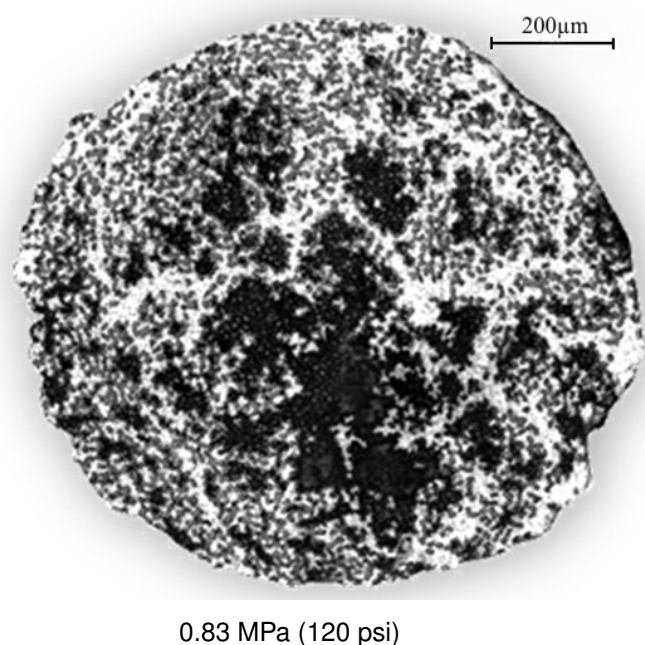

Fig. 2. Effect of the infiltration pressure on the porosity

The relative gap between the fibres varies within a wide range in case of composite wires. Relative gap is the smallest separation of the fibres divided by the fibre diameter. In general, the gap equals the surface roughness of the fibres but in some cases the gap is several times larger than the diameter of the fibres. Cross-section of the applied Nextel 440 alumina fibres is oval in shape (longitudinal axis is $14 \mu \mathrm{m}$, transverse axis is $8 \mu \mathrm{m}$ ). Therefore, Kaptay's method, which was developed for round fibres, is suitable only for approximate calculations. Kaptay provides a standard value for changing relative gap. According to this the smallest relative spaces between the fibres is in the range of 0,0-0,1. Appropriate image analysis method [14] is necessary to get more accurate determination of the relative gap between the fibres. The contact angle between aluminium and alumina (which is the main component of Nextel 440 ceramic fibres) was approximately $140^{\circ}$ at the production temperature of composite wires $\left(720^{\circ} \mathrm{C}\right)[15]$. The contact angle can be smaller than $140^{\circ}$ depending on the fact whether there is an oxide layer on the surface of the liquid metal or not [16, 17]. In case of continuous processes the source of oxygen is the air trapped between the fibres. For the calculations the surface tension was considered $0.6 \mathrm{~J} / \mathrm{m}^{2}$. Fig. 1 shows the results of these calculations.

Fig. 2] shows the micrographs of the cross-sections of composite wires. These composite wires were produced under different pressure. The black areas in the pictures are the unfilled pores.

The increase of the infiltration pressure decreases the area of the dark, unfilled pores (Fig. 2). In the experiment, it was not possible to increase the pressure above $1,65 \mathrm{MPa}$ at the given production speed. The lowest pressure applied to the examined composite wires was $0,83 \mathrm{MPa}$ because under this pressure the resulted composite wires did not contain enough aluminium to hold the fibre boundle together and no reliable volume fraction measurement could be carried out.

The characterisic of the changing porosity can be determined with an average value. The area of aluminium can be measured accurately in the pictures. Accordingly, Fig. 3 shows the relative
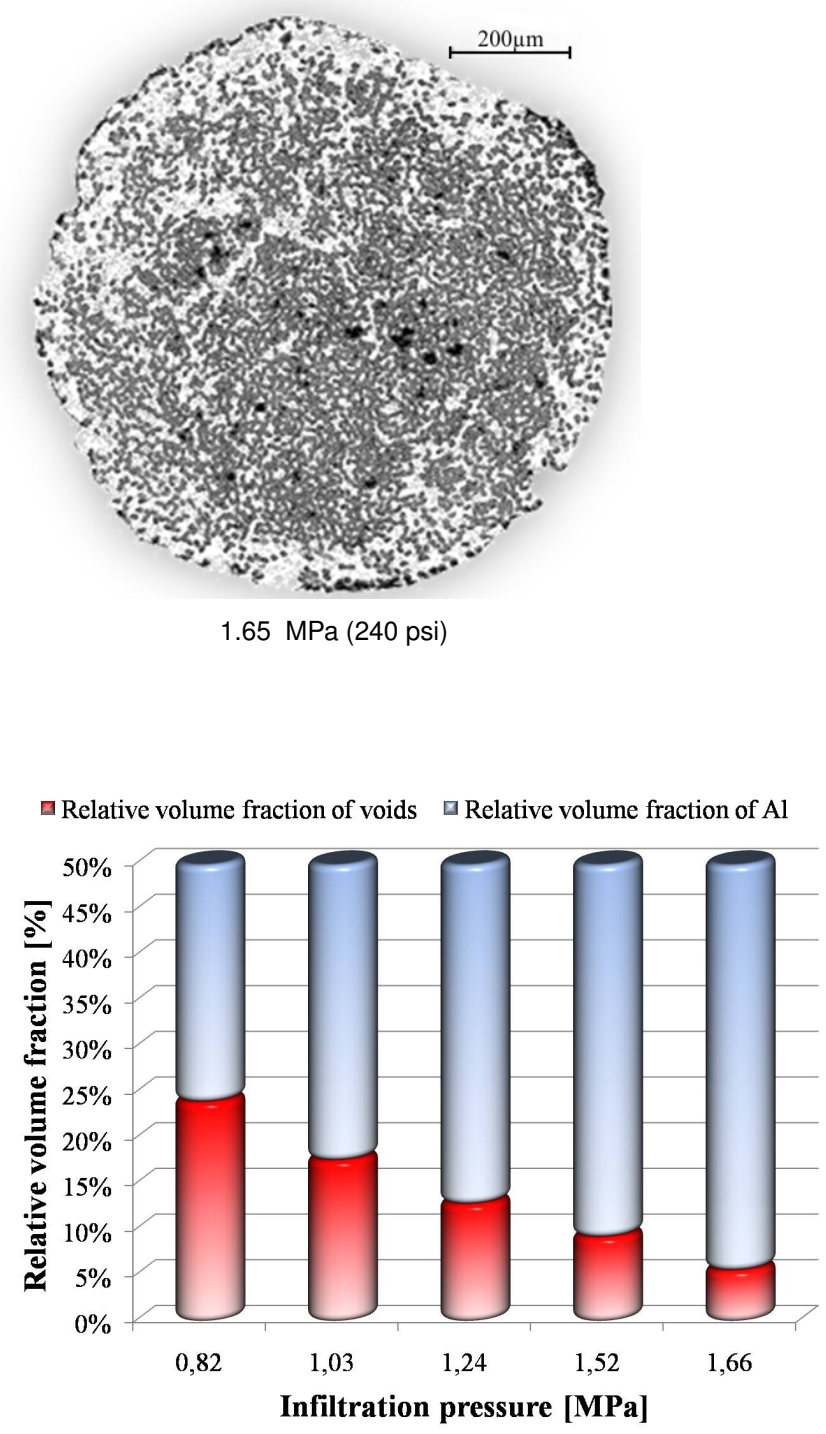

Fig. 3. Relative volume fraction of $\mathrm{Al}$ as function of infiltration pressure

aluminium volume fraction, which was measured in the crosssectional photos as function of the infiltration pressure with the error of the measured value. The relative aluminium volume fraction can be obtained from the correlation of the measured value to the theoretical maximum. The theoretical maximum value is the difference of average area of the composite wire and the area of fibres.

The porosity is decreasing with the increasing of infiltration pressure. These observations are only valid in the examined infiltration pressure range (0.83 $\mathrm{MPa}-1.65 \mathrm{MPa})$.

Fig. 4 shows the results of the tensile tests. The initial crosssections were determined from the measurements of micrographs. The composite wires which were produced with 1.03 MPa (150 psi) infiltration pressure give us the highest UTS (U1timate Tensile Strength). With this production set up the crosssection areas are the smallest, so the high UTS can cause the relative small cross-section area. On the other hand on 1,034 MPa infiltration pressure resulted maximum tensile force also. The infiltration pressure takes effect on the cross-section area of the composite wires and the cross-section areas have minimum 


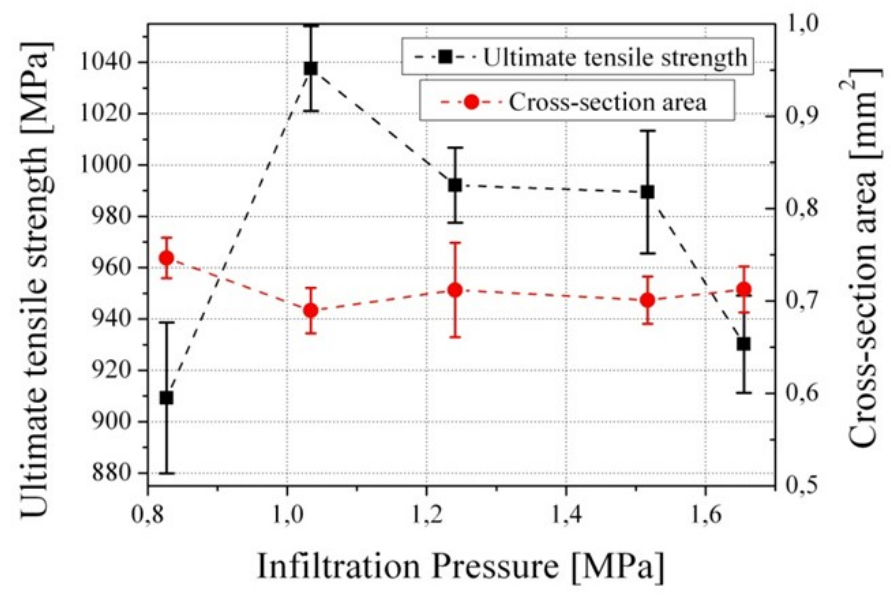

Fig. 4. UTS and cross-section area as function of infiltration pressure

value depending on the infiltration pressure. Forasmuch in the composite wires the strength of the fibres is dominant so if there are not significant changes in the tensile force the changing at the cross-section area is enough to explain the results.

\section{Conclusions}

Ten samples were taken of all five lots for the examinations. These composite wires were made under five different infiltration pressure conditions. The fibres with pores were separated from the matrix based on their colours via image editor software. The number of pixels from a given colour is proportional to the volume fraction of the given component. The results were plotted with their errors. Based on the graph the relationship between the pressure and porosity was determined. This relationship is linear (porosity inversely proportional to the infiltration pressure) in the examined pressure range.

The maximal ultimate tensile strength arises with 1,034 $\mathrm{MPa}$ infiltration pressures which are different from our expectations, thanks to the decreased cross-section area.

\section{References}

1 Blucher J T, Narusawa U, Katsumata M, Németh A, Continuous manufacturing of fiber-reinforced metal matrix composite wires-technology and product characteristics, Composites Part A 32 (2001), 1759-1766, DOI 10.1016/S1359-835X(01)00024-0.

2 Williams M G, Isaacs J A, Nadler J H, Sampson S L, Kowalski G J, Blucher $\mathbf{J} \mathbf{T}$, Analytically motivated process improvements in continuous metal-matrix composite wire fabrication, Materials Science and Engineering A266 (1999), 86-92, DOI 10.1016/S0921-5093(99)00039-8.

3 Blucher J T, Katsumata M, Process for fabrication of metal-carbon fiber matrix composite material, 2003.

4 Blucher $\mathbf{J} \mathbf{T}$, Reinforced structural elements incorporating fiber-reinforced metal matrix composite wires and methods of producing the same, 2003.

5 Blucher J T, Gating system for continuous pressure infiltration process, 1998.

6 Blucher J T, Dobranszky J, Narusawa U, Aluminium double composite structures reinforced with composite wires, Materials Science and Engineering A 387-389 (2004), 867-872, DOI 10.1016/j.msea.2003.11.083.

7 Weidenmann K A, Schomäker M, Kerscher E, Löhe D, Kleiner M, Com- posite extrusion of aluminum matrix specimens reinforced with continuous ceramic fibers, Light Metal Age 63 (2005), 6-10.

8 Kaptay G, The threshold pressure of infiltration into fibrous preforms normal to the fibers' axes, Composites Science and Technology 68 (2008), 228-237, DOI 10.1016/j.compscitech.2007.04.023.

9 Matsunaga T, Ogata K, Hatayama T, Shinozaki K, Yoshida M, Effect of acoustic cavitation on ease of infiltration of molten aluminum alloys into carbon fiber bundles using ultrasonic infiltration method, Composites Part A 38 (2007), 771-778, DOI 10.1016/j.compositesa.2006.09.003.

$10 \ldots$, Fabrication of continuous carbon fiber-reinforced aluminummagnesium alloy composite wires using ultrasonic infiltration method, Composites Part A 38 (2007), 1902-1911, DOI 10.1016/j.compositesa.2007.03.007.

11 Czigány T, Hibrid szálerôsítésü polimer kompozitok, Anyagvizsgálók Lapja 2 (2004), 59-62.

12 3M, Aluminum Conductor Composite Reinforced Technical Notebook, 2004.

13 Gácsi Z, Sárközi G, Réti T, Kovács J, Csepeli Zs., Mertinger V, Sztereológia és képelemzés, Well-PRess Kiadó Kft., Miskolc, 2001.

14 Szalay I, Gácsi Z, Magyar A, Karbonszál-erösítésú, alumíniummátrixú kompozit elốállítása és szerkezetének vizsgálata, BKL Kohászat 133 (2000), 279-284.

15 Sangghaleh A, Halali M, An investigation on the wetting of polycrystalline alumina by aluminium, Journal of Materials Processing Technology 197 (2008), 156-160, DOI 10.1016/j.jmatprotec.2007.06.024.

16 Kaptay Gy, Bolyán L, Interfacial aspects of producing MMCs. Part II/1. Databank of interfacial energies, BKL Kohászat 131 (1998), 179-185.

17 _ Interfacial aspects of producing MMCs. Part II/2. Databank of interfacial energies, BKL Kohászat 131 (1998), 305-314. 